\title{
ROLE OF MIDDLE CEREBRAL ARTERY AND DUCTUSVENOSUS DOPPLER IN EVALUATION OF INTRAUTERINE GROWTH RESTRICTION
}

\author{
By
}

\section{Ahmed Abd El-Sattar Al-Sayed Yakout, Abd El-Monaem Mohamed Zakaria and Ahmed Mohammed Saeed}

Department of Obstetrics and Gynecology, Faculty of Medicine, Al-Azhar University, Cairo, Egypt

Corresponding author: Ahmed Abd El-Sattar Al-Sayed Yakout, E-mail: ahmed.yakout89@gmail.com

\begin{abstract}
Background: World over, intrauterine growth restriction (IUGR) is observed in about $24 \%$ of newborns. Approximately, 30 million infants suffer from IUGR every year. IUGR is associated with stillbirth, neonatal death, and perinatal morbidity as well as delayed effects including cerebral palsy (CP) and adult diseases.

Objective: To assess the role of umbilical artery, middle cerebral artery and ductus venosus doppler in evaluating the neonatal outcome of growth restricted fetuses.

Patients and methods: Our study was conducted on 100 pregnant women attended at the department of Obstetrics and Gynecology, Al-Azhr University Hospitals from January 2019 to December 2019. The cases were allocated into 2 main groups: Group I: thirty two pregnant women with intrauterine growth restriction (IUGR), Group II: sixty eight normal pregnant women without IUGR.

Results: The presence of high statistical significance correlation between neonatal outcome and Doppler indices of umbilical artery, middle cerebral artery (PSV, PI, RI) in IUGR group. There were also high statistical significance correlation between neonatal outcome and Ductus venosus Doppler with high specificity and sensitivity of A wave RI, PI in IUGR group.

Conclusion: The umbilical artery Doppler indices (RI, PI) were abnormally high in IUGR, in addition with $\mathrm{S} / \mathrm{D}$ ratio have significant relation with poor neonatal outcome in IUGR fetuses. Middle cerebral artery Doppler indices (PSV, S/D ratio, RI and PI) are abnormally high in IUGR and have high significant relation with poor neonatal outcome in IUGR group.
\end{abstract}

Keywords: Middle Cerebral Artery \& Ductus, Doppler, IUGR.

\section{INTRODUCTION}

Intrauterine growth restriction (IUGR) is defined as a fetus that is at or below the 10th percentile in weight for its gestational age as adopted by the ACOG and the RCOG (Gluckman et al., 2010).

While overall fetal smallness is associated with poorer outcome, clinical evidence suggests that there are, at least, two groups of small fetuses, fetal growth restriction (FGR) versus constitutional small-for-gestational age (SGA). FGR is normally used to refer to small fetuses with higher risk for fetal in utero deterioration, stillbirth and overall poorer perinatal outcome as compared with normally grown fetuses. These fetuses are 
thought to have 'true' growth restriction. In general, FGR is associated with Doppler signs suggesting hemodynamic redistribution as a reflection of fetal adaptation to under nutrition/ hypoxia, histological and biochemical signs of placental disease and a higher risk of preeclampsia (Figueras and Gratacos, 2014).

Maternal habitus and physiology largely influences birth size, showing an association between height, uterine size, and blood flow. The Doppler indices; such as systolic/diastolic ratio, resistance index and pulsatility index, indirectly reflect the impedence of the circulation downstream to the point of insonation, and there is a significant association between abnormal Doppler indices and fetal hypoxia, fetal acidosis and adverse perinatal outcome (Kaponis et al., 2011).

Clinical studies of umbilical arterial flow velocity waveforms in IUGR have reported a progressive increase in impedance to flow until end-diastolic flow becomes absent and, in extreme cases, reversed (Al Qahtani, 2011).

In pregnancies with absent or reversed diastolic (A/RED) flow, the capillary loops in terminal villi are decreased in number, longer and with fewer branches than in normal pregnancies. For this reason, there is a strong association between the A/RED velocity and hypoxia/acidosis (Petraglia et al., 2012). When there is reversed flow, it may be a clinical emergency because most of these fetuses will die within 2 weeks. The A/RED flow, as a test for hypoxia, shows a high sensitivity, specificity, positive predictive value and negative predictive value (Mari et al., 2010).
The MCA Doppler is the most commonly imaged intracranial vessel due to its reproducibility and ease of identification. In the IUGR-affected fetus, an increase in diastolic blood velocity to the brain may be witnessed by MCA Doppler (Baschat et al., 2011). This is detected by a decrease in the S/D ratio or pulsatility index and is referred to as a brain sparing effect or cerebralization of umbilical blood flow. This is due to chronic hypoxia with redistribution of blood flow and as a consequence vasodilations in cerebral arteries occur. Arterial Doppler abnormalities detected in umbilical and middle cerebral arteries are early warning signs in IUGR. Otherwise, the fetal venous Doppler abnormalities indicate a more advanced stage of fetal compromise (Cosmi et al., 2011).

The aim of the work was to assess the role of umbilical artery, middle cerebral artery and ductus venosus Doppler in evaluating the neonatal outcome of growth restricted fetuses.

\section{PATIENTS AND METHODS}

This study was conducted at the department of Obstetrics and Gynecology, Al-Azhar University Hospital on 100 pregnant females in third trimester pregnancy selected from the attendees. Following counseling and explanation of all the procedure to the subjects and assurance of confidentiality and anonymity. An informed consent was obtained from all subjects in the two study groups. This study was approved by the Ethical Committee of the Al-Azhar University.

Inclusion criteria: Maternal age from 1840 years. Gestational age: second and 
third trimester's pregnancies and singleton pregnancy.

Exclusion criteria: Fetuses with structural anomalies, chronic hypertension, diabetes mellitus, multiple gestations and uncertain gestational age.

\section{Patients were subdivided in two groups:}

Group I: Thirty two pregnant women with IUGR and Group II: Sixty eight pregnant women with appropriate fetal growth.

All patients were subjected to history taking, general medical examination, Obstetrical examination, Abdominal examination, vaginal examination and routine laboratory investigations.

\section{Specific investigations:}

i. Non-stress test: The test involved attaching one electrode to the mother's abdomen to measure fetal heart rate and another belt to measure contractions.

ii. Ultrasonographic scanning for the assessment of gestational age for all the cases in the study, fetal biophyisical profile, estimated date of delivery, expected fetal weight using Hadlock regression formula, presence of IUGR. Fetal biometry (BPD, HC, AC, FL, and TCD) for estimation of gestational age, evaluation of fetal growth and diagnosis of IUGR after two serial examinations to evaluate fetal growth curve) and diagnosis of IUGR. Amniotic fluid index, exclusion of anomalies.Assessment of the placenta.
iii.Doppler study of Umbilical artery (UA), middle cerebral artery (MCA) and ductus venosus (DV).

Delivery was evaluated regarding, gestational age at delivery, mode of delivery, and the presence or absence of complications. All born neonates were examined by a neonatologist in order to assess the Apgar score and birth weight. 5-minute Apgar score was estimated by evaluating the new born according to five criteria; namely appearance, pulse, grimace, activity and respiration. Following delivery, perinatal outcome were evaluated by means of four variables: the need for admission to the neonatal intensive care unit (NICU), need for neonatal intubation, and significant neonatal morbidity (presence of central nervous system complications).

\section{Statistical analysis:}

Results of the present study were statistically analyzed using SPSS 25 (IBM, USA). Data were represented as Mean \pm SD or number and percentage. Numerical data were compared using Fisher exact test or Chi-square test as appropriate. ROC curve was used to evaluate the performance of different tests differentiate between certain groups. The level of significance was taken at $\mathrm{P}$ value $<0.050$ is significant, otherwise is nonsignificant. 


\section{RESULTS}

No significant difference between IUGR and non-IUGR cases regarding LMP (38.1 $\pm 1.5,38.0 \pm 1.6$ respectively; $\mathrm{p}=0.818)$. While Estimated (32.9 \pm 2.3 , $38.6 \pm 1.7$ respectively; $\mathrm{p}<0.001)$ and Gap
(LMP- estimated) $\quad(-5.2 \pm 1.3, \quad 0.6 \pm 0.6$ respectively; $\mathrm{p}<0.001)$ were significantly lower in IUGR cases than in non-IUGR cases (Table1).

Table (1): Comparison according to IUGR regarding gestational age (week) among the studied cases

\begin{tabular}{|l|c|c|c|}
\hline \multicolumn{1}{|c|}{ Methods } & $\begin{array}{c}\text { IUGR } \\
(\mathbf{N = 3 2})\end{array}$ & $\begin{array}{c}\text { Non-IUGR } \\
(\mathbf{N = 6 8})\end{array}$ & ^P-value \\
\hline LMP & $38.1 \pm 1.5$ & $38.0 \pm 1.6$ & 0.767 \\
\hline Estimated & $32.9 \pm 2.3$ & $38.6 \pm 1.7$ & $<\mathbf{0 . 0 0 1}$ \\
\hline Gap (LMP- estimated) & $-5.2 \pm 1.3$ & $0.6 \pm 0.6$ & $<\mathbf{0 . 0 0 1}$ \\
\hline
\end{tabular}

${ }^{\wedge}$ Independent $\mathrm{t}$-test.

UA PI $\quad(0.88 \pm 0.13, \quad 0.79 \pm 0.13$ respectively; $\mathrm{p}=0.002$ ) was significantly higher in IUGR cases than in non-IUGR cases. MCA PI $(0.93 \pm 0.19,1.19 \pm 0.32$ respectively; $\mathrm{p}<0.001), \mathrm{CPR}(1.06 \pm 0.15$, $1.49 \pm 0.22$ respectively; $\mathrm{p}<0.001)$, DV PI
$(0.51 \pm 0.10, \quad 0.70 \pm 0.11 \quad$ respectively; $\mathrm{p}<0.001)$ and DV A-wave $(33.6 \pm 11.4$, $42.0 \pm 12.3$ respectively; $p=0.002$ ) were significantly lower in IUGR cases than in non-IUGR cases (Table 2).

Table (2): Comparison according to IUGR regarding Doppler findings

\begin{tabular}{|l|c|c|c|}
\hline \multicolumn{1}{|c|}{ Variables } & $\begin{array}{c}\text { IUGR } \\
\mathbf{( N = 3 2 )}\end{array}$ & $\begin{array}{c}\text { Non-IUGR } \\
(\mathbf{N}=\mathbf{6 8})\end{array}$ & ${ }^{\wedge}$ P-value \\
\hline UA PI & $0.88 \pm 0.13$ & $0.79 \pm 0.13$ & $\mathbf{0 . 0 0 2}$ \\
\hline MCA PI & $0.93 \pm 0.19$ & $1.19 \pm 0.32$ & $<\mathbf{0 . 0 0 1}$ \\
\hline CPR & $1.06 \pm 0.15$ & $1.49 \pm 0.22$ & $<\mathbf{0 . 0 0 1}$ \\
\hline DV PI & $0.51 \pm 0.10$ & $0.70 \pm 0.11$ & $<\mathbf{0 . 0 0 1}$ \\
\hline DV A-wave & $33.6 \pm 11.4$ & $42.0 \pm 12.3$ & $\mathbf{0 . 0 0 2}$ \\
\hline
\end{tabular}

$\wedge$ Independent t-test.

Birth weight $\quad(2.0 \pm 0.3, \quad 3.1 \pm 0.4$ respectively; $\mathrm{p}<0.001)$ was significantly lower in IUGR cases than in non-IUGR cases. NICU admission (46.9\%, 2.9\%; $\mathrm{p}<0.001)$, Intrauterine fetal death $(15.6 \%$,
$0.0 \% ; \mathrm{p}=0.003)$ and Neonatal death $(6.3 \%, \quad 0.0 \% ; \quad \mathrm{p}=0.100)$ were more frequent in IUGR cases than in non-IUGR cases, the difference were significant except in Neonatal death (Table 3).

Table (3): Comparison according to IUGR regarding Neonatal outcomes

\begin{tabular}{|l|c|c|c|}
\hline \multicolumn{1}{|c|}{ Methods } & IUGR (N=32) & Non-IUGR (N=68) & P-value \\
\hline Birth weight (kg) & $2.0 \pm 0.3$ & $3.1 \pm 0.4$ & ^<0.001 \\
\hline NICU admission & $15(46.9 \%)$ & $2(2.9 \%)$ & $\#<\mathbf{0 . 0 0 1}$ \\
\hline Intrauterine fetal death & $5(15.6 \%)$ & $0(0.0 \%)$ & $\mathbf{\$ 0 . 0 0 3}$ \\
\hline Neonatal death & $2(6.3 \%)$ & $0(0.0 \%)$ & $\$ 0.100$ \\
\hline
\end{tabular}

$\wedge$ Independent t-test. \# Chi square test. §Fisher's Exact test. 
There was significant negative correlation between Gap (LMPestimated) and UA PI (-0.288). There were significant negative correlations between Gap (LMP- estimated) and MCA PI, CPR, DV PI and DV A-wave(0.382, $0.691,0.624$ and 0.278 respectively) (Table 4).

Table (4): Correlation between Gap (LMP- estimated) and Doppler findings

\begin{tabular}{|l|c|c|}
\hline \multicolumn{1}{|c|}{ Variables } & R & P \\
\hline UA PI & -0.288 & $\mathbf{0 . 0 0 4}$ \\
\hline MCA PI & 0.382 & $<\mathbf{0 . 0 0 1}$ \\
\hline CPR & 0.691 & $<\mathbf{0 . 0 0 1}$ \\
\hline DV PI & 0.624 & $<\mathbf{0 . 0 0 1}$ \\
\hline DV A-wave & 0.278 & $\mathbf{0 . 0 0 3}$ \\
\hline
\end{tabular}

Total $=100 .{ }^{\wedge}$ Pearson correlation

AUC of UA PI, MCA PI, CPR, DV PI and DV A-wave had significant diagnostic performance in the diagnosis of IUGR, were $0.693,0.762,0.958,0.900$ and 0.695 respectively; was highest in CPR (Figure 1).

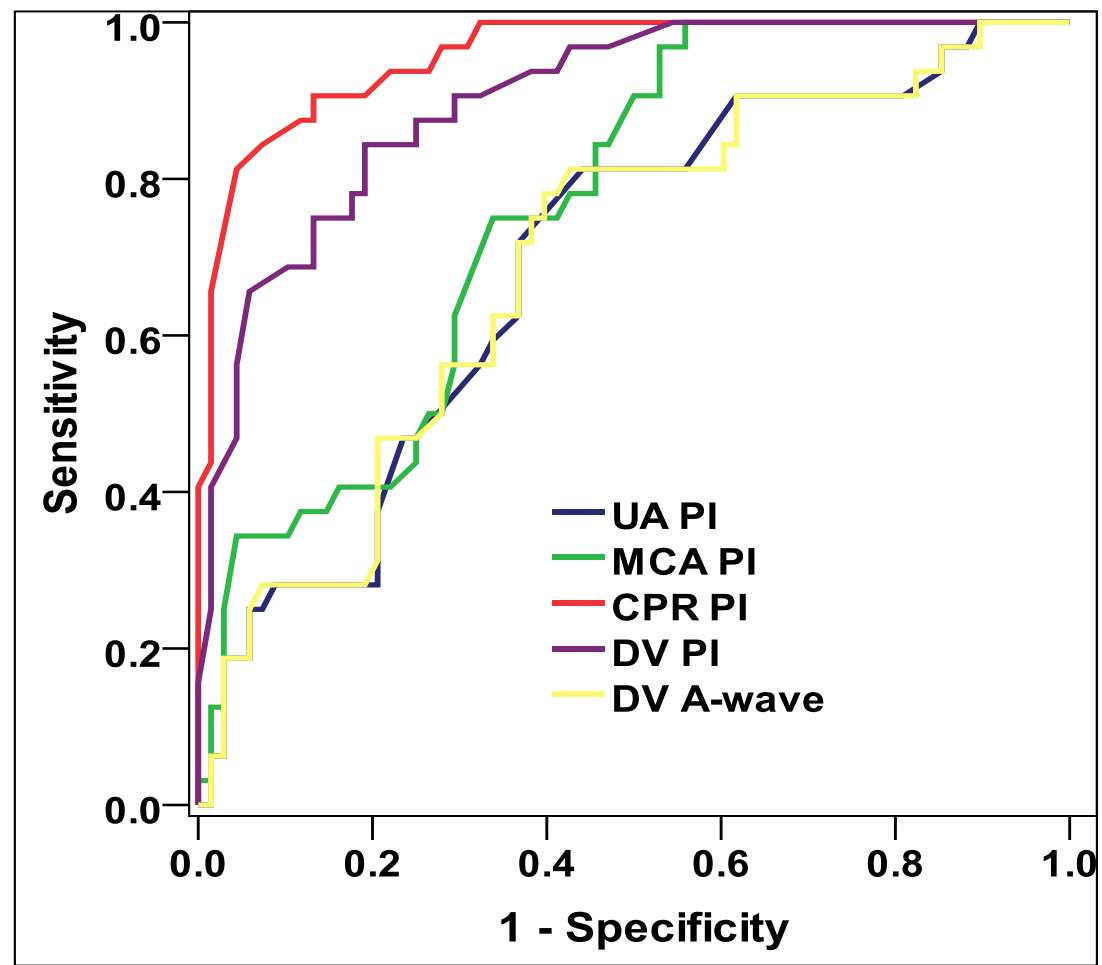

Figure (1): $\quad$ ROC curve for Doppler findings in the diagnosis of IUGR

Diagnostic characteristics of Doppler findings cutoff points in the diagnosis of IUGR show that CPR $\leq 1.19$ had highest diagnostic characteristics in the diagnosis of IUGR (Figure 2). 


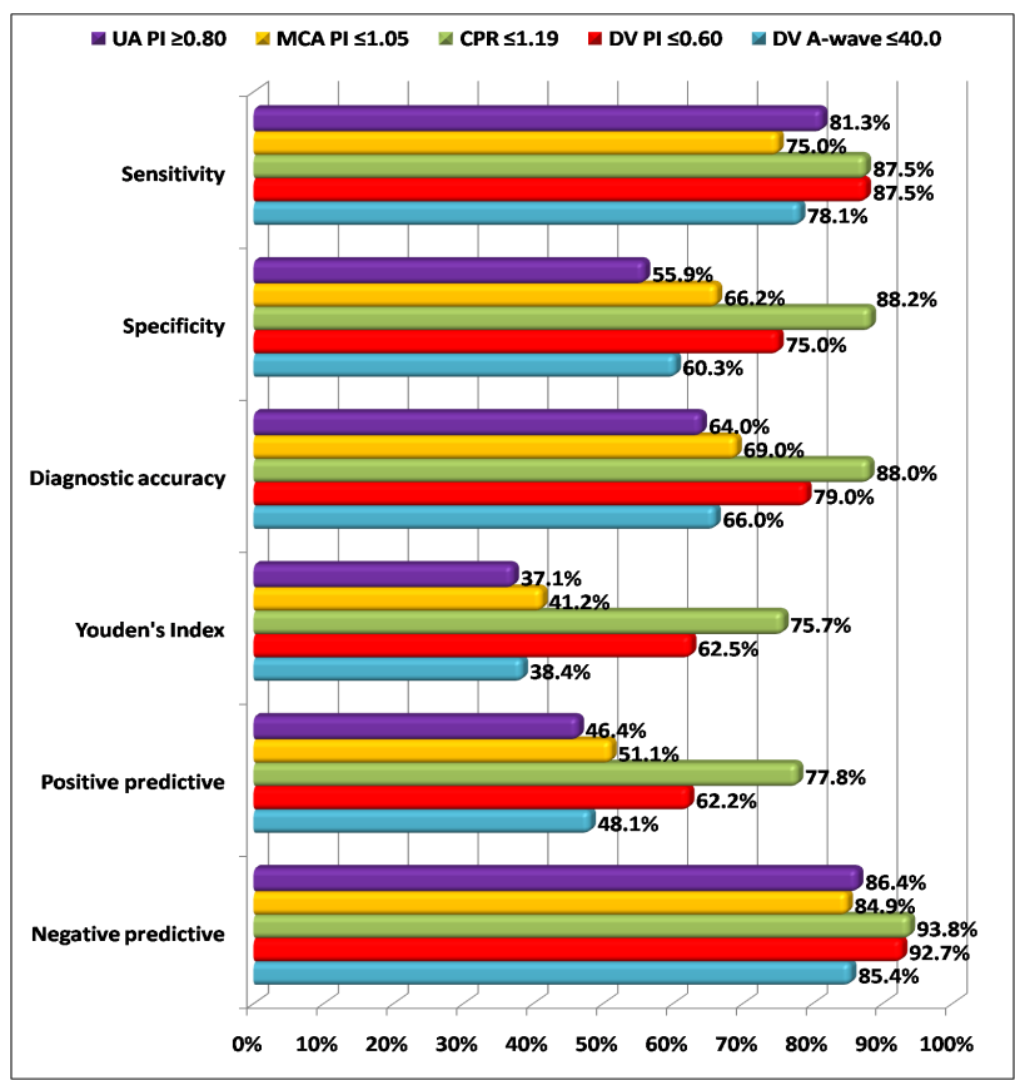

\section{Figure (2): Diagnostic characteristics of Doppler findings cutoff points in the diagnosis of IUGR}

\section{DISCUSSION}

Our results showed significant statistical correlation between abnormal neonatal outcome (IUFD, admission to NICU, neonatal death) with abnormal umbilical artery Doppler indices in group I (S/D ratio, PI and RI). These data were consistent with study of Neilson and Alfirevic (2010) who conducted a metaanalysis on high-risk pregnancies has demonstrated a significant improvement of a number of perinatal outcomes, with overall reduction of perinatal mortality of $30 \%$.

A Cochrane review by Alfirevic et al. (2010) had shown that fetal and umbilical artery Doppler ultrasound in high risk pregnancies can decrease the perinatal mortality by $29 \%$ when obstetric services were in place to ensure safe and timely delivery of the baby when needed. Spinillo et al. (2011) conducted a cohort study at 24-35 weeks gestational age complicated by IUGR and abnormal umbilical artery Doppler measurements. They concluded that IUGR with absent or reversed UA end diastolic flow, vasodilatation of the MCA is a risk factor for neonatal death or brain damage.

Our study results demonstrated that there were statistical significance regarding (S, D, S/D ratio, RI, PI) Doppler indices of middle cerebral artery (MCA) in relation to neonatal outcome in group I. Mari et al. (2012) conducted a retrospective cross-sectional study of 30 IUGR fetuses and they concluded that, in IUGR fetuses, the high MCA-PSV 
predicts perinatal mortality better than low MCA-PI.

The cerebral/umbilical pulsatility ratio $(\mathrm{C} / \mathrm{U}$ ratio) has been recognized as the more sensitive and specific indicator of likelihood of IUGR and adverse perinatal outcome in high-risk pregnancies. Comparison between the two groups regarding patient's MCA PI / Umbilical artery (Umb a) PI showed statistical significant difference. Вапи (2011) measured RI and PI in UA and MCA and also the RI\& PI ratios between these arteries. The result of this study indicated that measurement of PI value in the UA is enough to detect IUGR, probably due to reflection of decrease placental vascular bed, but the ratio of indices between UA and MCA is more accurate than independent evaluations in identifying fetuses developing distress, reflecting a brain sparing effect as well as fetoplacental insufficiency. Hung et al. (2010) concluded that combining the PI of the UA and DV provides greatest accuracy in predicting growth restricted neonates with acidemia. Bano et al. (2010) concluded that the MCA/UA ratio is a better predictor of SGA fetuses and adverse perinatal outcome than the MCA PI or the UA PI used alone; the UA PI can be used to identify IUGR, and the MCA PI alone is not a reliable indicator for predicting fetal distress. Jurisić et al. (2010) concluded that the reliability of MCA/UA ratio in the estimation of fetal condition in pre-eclamptic patients is high. Very low MCA/UA ratio values in patients with pre-eclampsia indicate that in these fetuses, fetal acidosis and fetal distress may be expected.
The Ductus Venosus (DV) allows the diversion of highly oxygenated blood from the umbilical vein into the right atrium throught the foramen ovale to the left side of the heart and hence to irrigate the fetal brain (Mari et al., 2012). Our result revealed strong statistical evidence of poor neonatal outcome with abnormal DV Doppler indices (mainly A wave, RI, PI), with $p$ value $(0,000,0.028)$ respectively in group I. Our findings were in close relation with Axt-Fliedner et al. (2010) findings; the similarity with their result was probably due to the use of the same insonation angle correction.

References were higher than those obtained by Pokharel and Alam (2017) the difference was attributed to the fact that the former study showed a smaller sample size than our study and did not correlate the pulsatility index with the gestational age with scattered distribution. However, their values were below 1.0 in all gestational ages.

Late Doppler changes including an elevated DV Doppler index and reversed umbilical artery end-diastolic velocity were observed in the week prior to delivery in up to $40 \%$ of fetuses. They documented parallel progression of cerebral and precordial venous Doppler abnormalities (Turan et al., 2010).

Picconi et al. (2010) assessed ductus venosus wave forms qualitatively; forward flow versus reversed or absent flow in diastole. They proved that there is a transition phase in which DV alternates forward flow and absent or reversed A wave before reversed A wave become persistent, the time from the appearance of DV reversed flow to IUFD is variable and 
so it has to be integrated with other antenatal fetal parameters.

In the IUGR pre-eclampsia studies, the number of obstetric interventions was significantly reduced in pregnancies monitored with Doppler ultrasound including antenatal admissions, inductions of labor, and cesarean section (Schild et al., 2013).

\section{CONCLUSION}

The umbilical artery Doppler indices (RI, PI) were abnormally high in IUGR, in addition with $\mathrm{S} / \mathrm{D}$ ratio have significant relation with poor neonatal outcome in IUGR fetuses. Middle cerebral artery Doppler indices (PSV, S/D ratio, RI and PI) were abnormally high in IUGR and have high significant relation with poor neonatal outcome in IUGR group. Ductus venosus Doppler indices (PI, A wave) were significantly abnormal in IUGR fetuses and have high significant relation with poor neonatal outcome in IUGR group. However, the use of multiple parameters for assessment of the fetal wellbeing simultaneously was the most beneficial in predicting the neonatal outcome, but this needs referral for perinatologist.

Arterial Doppler abnormalities detected in umbilical and middle cerebral arteries were early warning signs in IUGR. Otherwise, the fetal venous Doppler abnormalities indicated a more advanced stage of fetal compromise.

Conflicts of interest: No conflicts of interest were encountered.

\section{REFERENCES}

1. Alfirevic $Z$, Stampalija $T$ and Gyte GM. (2010): Fetal and umbilical Doppler ultrasound in high risk pregnancies. Cochrane Database Syst Rev., (1):CD007529.

2. Al Qahtani N. (2011): Doppler Ultrasound in the assessment of suspected intra-uterine growth restriction. Ann Afr Med., 10(4):266271.

3. Axt-Fliedner $\mathbf{R}$, Diler $\mathbf{S}$ and George $\mathbf{T}$. (2010): Reference values of ductusvenosus blood flow velocities and waveform indicies. Arch Gynecol Obestet., 269:199-204.

4. Bano S, Chaudhary V and Pande S. (2010): Color doppler evaluation of cerebral-umbilical pulsatility ratio and its usefulness in the diagnosis of intrauterine growth retardation and prediction of adverse perinatal outcome. Indian J Radiol Imaging, 20(1):20-25.

5. Banu AA. (2011): Doppler velocimetry in the umbilical and middle cerebral arteries in fetuses with intrauterine growth retardation or fetal distress. FukokaIgaku Zasshi., 99(5):133144.

6. Baschat AA, Cosmi $\mathrm{E}$ and Bilardo CM. (2011): Predictors of neonatal outcome in early-onset placental dysfunction. American Journal of Obstetrics and Gynecology, 109:253-61.

7. Cosmi E, Saccardi C, Bogana G, Funai E, Berghella V and Mari G. (2011): Doppler and BPP as predictors of outcome in severe IUGR fetuses. American Journal of Obstetrics and Gynecology, 6: 197-209.

8. Figueras F and Gratacos E (2014): Stagebased approach to the management of fetal growth restriction. Prenat Diagn, 34:655-9.

9. Gluckman PD, Hanson MA, Cooper C and Thornburg KL. (2010): Effect of in-utero and early life conditions on adult health and disease.N Engl J Med., 359(1):61-73.

10.Hung JH, Fu CY and Hung J. (2010): Combination of fetal Doppler velocimetric resistance values predict academic growthrestricted neonates. J Ultrasound Med., 25(8): 957-962.

11. Jurisić A, Jurisić $Z$ and Pazin V. (2010): Fetal cerebral-umbilical Doppler ratio in prediction of fetal distress in patients with 
preeclampsia. Vojnosanit Pregl., 67(6):487492.

12. Kaponis A, Harada T, Makrydimas G, Kiyama $T$ and Adonakis G. (2011): The importance of venous Doppler velocimetry for evaluation of intrauterine growth restriction. J Ultrasound Med., 30(4):529-45.

13. Mari G, Brocato B, Donepudi RV and Preedy VR. (2012): Cardiovascular changes in IUGR. In: Handbook of growth and growth monitoring in health and disease. Pbl. New York, LLC, Pp. 275-97.

14. Mari G, Hanif F, Kruger M, Cosmi E and Treadwell MC. (2010): Middle cerebral artery peak systolic velocity: a new Doppler parameter in the assessment of growthrestricted fetuses. American Journal of Obstetrics and Gynecology, 29(3):310-6.

15. Neilson JP and Alfirevic Z. (2010): Doppler ultrasound for fetal assessment in high risk pregnancies. Cochrane Database Syst Rev., (2):CD000073.

16. Petraglia F, Boni C, Severi FM, Norman J. Buonocore $\mathbf{G}$, Bracci $\mathbf{R}$ and Weindling $M$. (2012): Neonatology: a practical approach to neonatal diseases. Pbl. Milan: Springer, Pp. 5566.
17. Picconi JL, Kruger $M$ and Mari G.(2010): Ductusvenosus S-wave/isovolumetric A-wave (SIA) index and A-wave reversed flow in severely premature growth-restricted fetuses. J Ultrasound Med., 27(9):1283-1289.

18. Pokharel $P$ and Alam AM. (2017): Fetal ductusvenosuspulsatility index and diameter during second and third trimester of gestation. Nepal Med Assoc., 56(205):124-131.

19. Schild RL. (2013): Obstetrical aspects In Caring for Children Born Small for Gestational Age. Pbl. Springer Healthcare, Pp. 77-81.

20.Spinillo A, Montanari L, Roccio M, Zanchi S, Tzialla C and Stronati M. (2011): Prognostic significance of the interaction between abnormal umbilical and middle cerebral artery Doppler velocimetry in pregnancies complicated by fetal growth restriction. Acta Obstet Gynecol Scand., 88(2):159-66.

21. Turan OM, Turan S, Gungor S, Berg C, Moyano D and Gembruch U. (2010): Progression of Doppler abnormalities in intrauterine growth restriction. American Journal of Obstetrics and Gynecology, 32:160167. 


\section{AHMED ABD EL-SATTAR YAKOUT et al.,}

\section{تقييم دور دوبلر الثريان المخي الأوسط والقناة الوريدية في

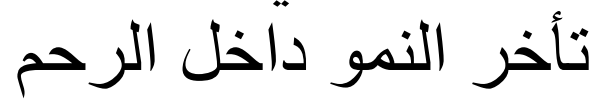

أحمد عبد الستار السيد ياقوت، عبد المنعم محمد زكريا، أحمد محمد سعيد

قسم أمراض النساء والتوليد، كلية الطب، جامعة الأزهر

E-mail: ahmed.yakout89@gmail.com

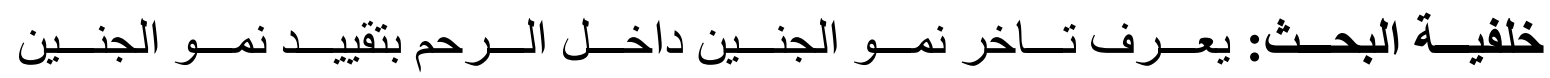

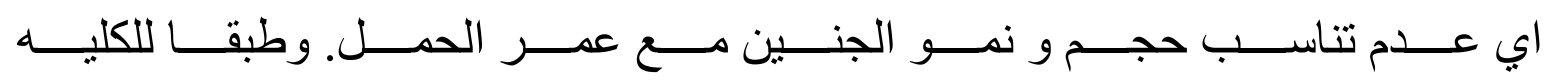

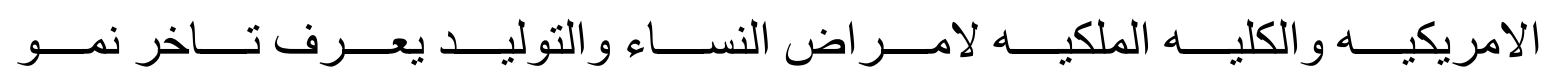

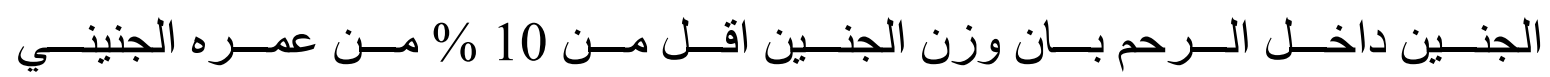

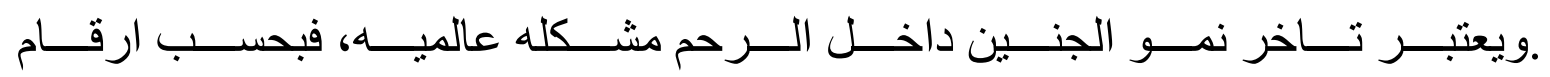

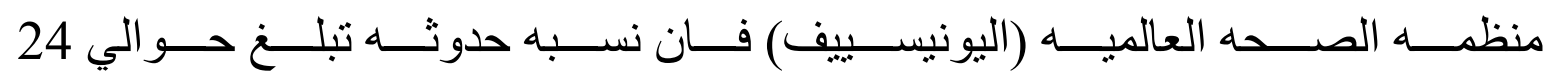
\% سنويا خاصه في قار ات اسيا و افريقيا و امريكا الجنوبيا.

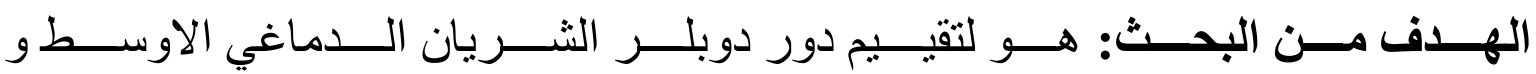
دوبلر القناة الوريدية في تقييم نتائج المو اليد من الأجنة النمو مقيدة.

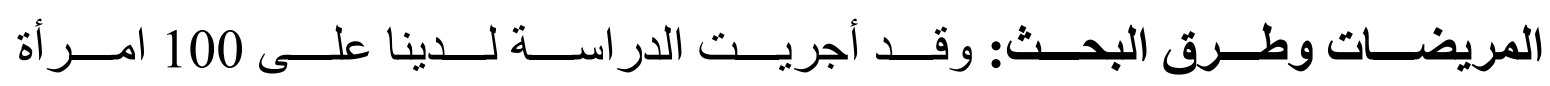

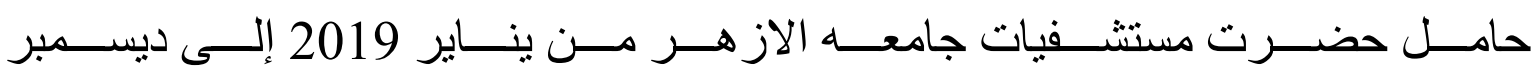

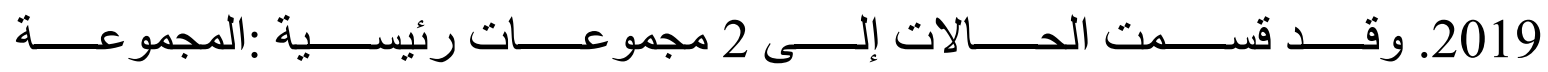

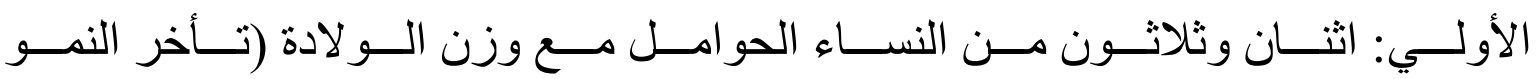

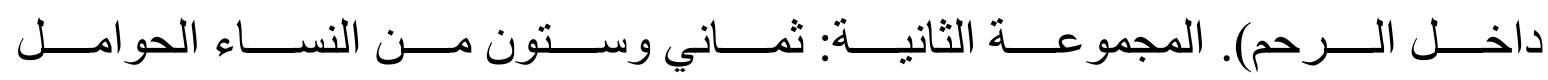

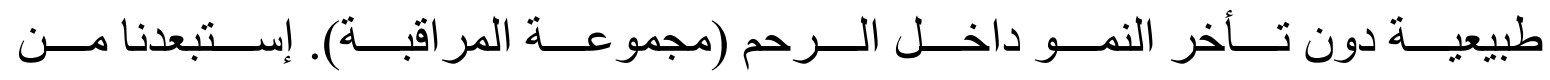

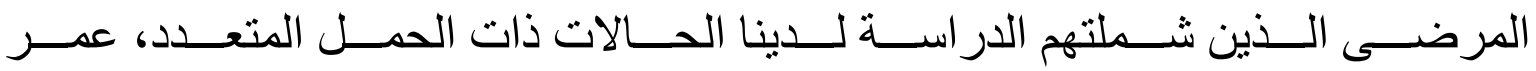
رحمى غير مؤكد و التشو هات الخلقية للجنين. 
ROLE OF MIDDLE CEREBRAL ARTERY AND DUCTUSVENOSUS...

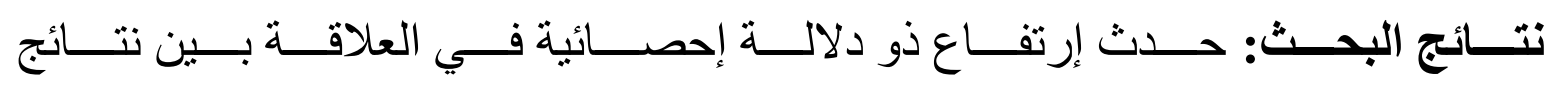

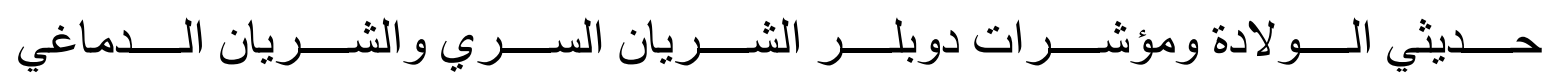

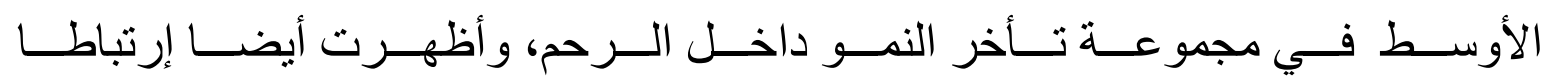

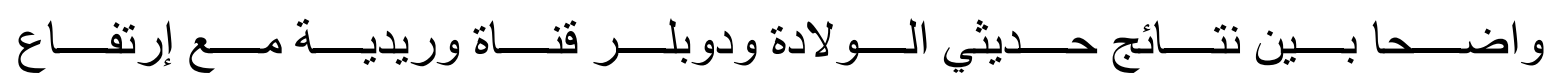
خصوصية وحساسية موجة (ا) في مجمو عة تأخر النمو داخل الرحم.

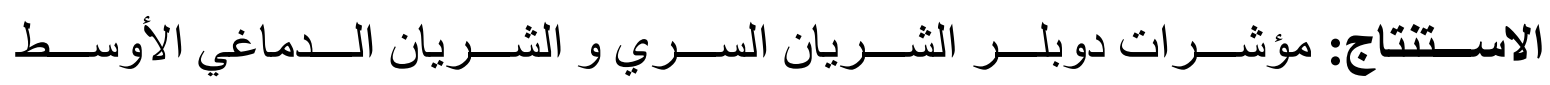
وقناة وريدية ذات دلالة و اضحة في إرتباطهم بنتائج حديثي الولادة.

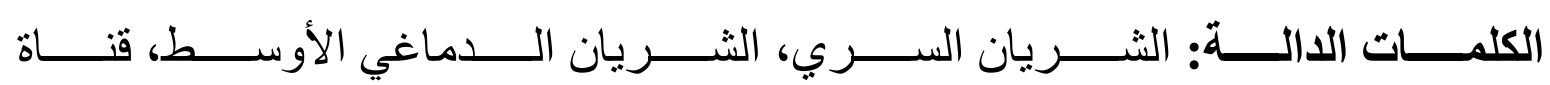
وريدية، دوبلر، تاخر نمو الجنين. 